\title{
Impact of a Neuro-Cognitive Intervention on Students' Cognitive Functions: Assessments in a Government School Setting in South India
}

\author{
Madhavi Bongarala ${ }^{1}$, Shashi Kumar ${ }^{2}$, Ronald Ross ${ }^{3}$, R. Manjunatha ${ }^{4}$, \\ N. S. Nagaraja ${ }^{5}$ \& Krishnamurthy Jayanna ${ }^{1,5}$ \\ ${ }^{1}$ Center for Integrative Health and Wellbeing, Bangalore, India \\ ${ }^{2}$ ESIC Medical College \& Postgraduate Institute of Medical Science and Research, Bangalore, India \\ ${ }^{3}$ Indian Administrative Services (IAS), Government of Telangana, India \\ ${ }^{4}$ Institute of Health Management Research, Bangalore, India \\ ${ }^{5}$ Cognitive Skills Pvt Ltd, Bangalore, India \\ Correspondence: Krishnamurthy Jayanna, \# 359, 16th main, 4th T Block East, Jayanagar, Bangalore 560011, \\ India. Tel: 91-934-123-6508. E-mail: krishnamurthyj@cihw.in
}

Received: May 20, 2019 Accepted: August 18, 2019 Online Published: August 21, 2019

doi:10.5539/jedp.v9n2p62 URL: http://doi.org/10.5539/jedp.v9n2p62

\begin{abstract}
Evidence indicates that cognitive deficits can affect students' performance in schools. An effort to enhance cognitive skills through integration of a neuro-cognitive training called 'Brighter Minds', was made in the government schools of South India during 2017-18. 110 students went through a pre and post training evaluation, using a mixed methods study design to assess changes in attention, observation and memory. Tools such as Make a Trail and Stroop test to assess attention, Word Recall and Visual stimulus tests for memory and acustomized tool to assess changes in observation were used. Focus group discussions were conducted to understand teachers' experience and acceptance of the training. Paired t-tests demonstrated statistically significant gains in all the three cognitive traits. The average time taken to complete the trail tests significantly reduced after the training (Trail A: $59.3 \mathrm{~s}$ to $47.5 \mathrm{~s}$; Trail B: $156 \mathrm{~s}$ to $120 \mathrm{~s} . \mathrm{p}<0.001$ ). The average number of correct items read out in the Stroop test improved significantly. More students were able to observe deeper aspects of the test object (23 Vs $40, \mathrm{p}<0.001)$. On intuition tests, average score of correct observations went up significantly from 6.7 to 9.6 objects. Memory assessments revealed significant improvements in verbal recall (both immediate and delayed) and visual recognition, but marginal improvements in visual retention. The teachers reported changes in student's motivation, discipline and participation. The training was seamlessly rolled out by the teachers during regular hours and led to improvements in students' cognitive abilities. The cognitive trainings offer promise to complement current efforts in enhance learning outcomes among students.
\end{abstract}

Keywords: cognitive training, attention, memory, observation, neuro-cognitive intervention, brain training

\section{Background}

Sustainable Development Goal (SDG) 4 aims to 'ensure inclusive and equitable quality education and promote lifelong learning for all' by 2030. In 2018, globally more than half of children and adolescents are not meeting minimum proficiency requirements in basic education. The situation is not very different in India. The higher education system in India ranks first with the highest number of institutions in the world and third with respect to the student enrolment, only after China and the United States (D. Gupta \& N. Gupta, 2012). A nationwide survey in 2016 covering 562,305 children in age group of 3 to 16 years showed that $42 \%$ and $27 \%$ children respectively demonstrated appropriate reading and arithmetic abilities for age. The results haven't varied much over the decade as previous evaluations in 2006 had demonstrated similar results i.e. $47 \%$ of grade 5 children being able to read story text of grade 2 difficulty and $25 \%$ of grade 8 children being able to solve a simple division problem (Kingdon, 2007). On contrary, the country was able to achieve good enrolment rates to the tune of $90 \%$ at the dawn of the current century and has consistently stayed close to universal enrolment for elementary education and over $90 \%$ mark for high school (Pratham, 2018). The reasons for poor learning outcomes despite good enrolment have been 
attributed to gaps in infrastructure and quality of teaching (Banerjee et al., 2007). Though policies such as Right to Education Act (RTE, 2009) and others have targeted school enrolment and indeed have shown some improvements over the years, they haven't necessarily translated to desired improvements in learning outcomes. The current educational policy and framework strongly articulates the need to address the persisting challenges in access, equality, quality and affordability (Mann, 2019).

Most of the time, these problems are addressed by increasing investments on infrastructure, additional teachers and tutoring programs. But the evidence of their impact on student performance is inconclusive (Hill, Serpell, \& Faison, 2016; Glewwe et al., 2004; Kremer \& Moulin, 2002). Efforts in India through strategies such as remedial education and computer assisted learning have been attempted and evaluated. They are cost effective and have shown to impact student performance significantly in the short term, but have failed to sustain outcomes for long periods (Banerjee, 2005). Probably there are other determinants for poor student performance which are yet to be understood and addressed within the existing policies and systems of education. In the recent past, there has been growing interest in exploring how cognitive deficits affect academic performance. Evidence shows that students with higher attention control, attention shifting and working memory tend to perform better academically than those with poor cognitive skills (Serpell \& Faison, 2016; Raghubar, Barnes, \& Hecht, 2010; Swanson \& Jerman, 2006; Biederman et al., 2004). Cognitive training often referred to as, brain training is explored in recent times to modify cognitive skills. Evidence shows that these interventions can bring about alternations of neural structure associated with learning (Willis et al., 2006). However, there is a dearth of studies on the long term impact of these interventions on academic success.

Encouraging outcomes in brain training include improvements in cognitive skills such as memory (Holmes \& Gathercole, 2014; Wiest et al., 2014), attention, processing speed and reasoning or logic (Rabiner et al., 2010; Tamm et al., 2013). In a study by Titz and Karbach (2014), children who underwent training in working memory and executive functions showed an improvement in academic performance. There have been efforts within educational settings to integrate research-based interventions to improve cognitive skills in addition to traditional interventions (Fuchs et al., 2008). Although substantial evidence supports the efficacy of cognitive training programs in improving cognition, the translation of cognitive changes into academic success needs further exploration (Jedlicka, 2017). Most of these studies have been conducted in the western settings. Within India, the uptake of these programs is still in infancy, and there is a potential opportunity to explore how cognitive training can complement existing efforts in enhancing learning outcomes.

The 'Brighter Minds' (BM) program is a brain training program offered by an Indian company with a vision to unlock the potential in children through enhancing their sensory perceptions and cognitive functions. The program consists of 30 hours of training for eight weeks with two consecutive sessions in the first week and seven follow-up sessions over the week-ends, each session lasting about 3-3.5 hours. The pedagogy uses the following tools and activities: (1) age and context appropriate physical exercises and dance to improve child participation and joy; (2) breathing exercises, relaxation and positive affirmations to calm the mind and body; (3) specific physical exercises to stimulate left and right brain activities and coordination; and (4) specifically developed music for alpha entrainment. Physical exercises and dance have been shown to increase intrinsic motivation in children (Gao, Padlock, \& Huang, 2013). Breathing exercises and relaxation have shown to reduce anxiety, especially state anxiety, improving the health of children suffering from asthma (Chiang et al., 2009). Also, coordinative exercises have been shown to be effective in concentration and attention domains of adolescents aged 13 to 16 years (Budde et al., 2008). Music for alpha entrainment is in tangent with binaural beats used for brainwave entrainment and have shown to have an effect on anxiety, attention, creativity, reaction time, working memory and cognitive flexibility (Padmanabhan, Hildreth, \& Laws, 2005; Crespo et al., 2012; Reedijk, Bolders, \& Hommel, 2013; Kraus, 2015; Hommel et al., 2016; Shekar et al., 2018). The Brighter Minds training program is offered to only those children who are not diagnosed with any psychological disorders and/or known major cognitive deficits. Initial anecdotal evidence after rolling out brighter minds training, showed encouraging results with respect to several cognitive traits of children such as observation, focus and intuition. In addition, a survey conducted amongst parents of those children who were trained in the program, showed changes in attention, memory, perceptual ability, comprehension, planning and self-confidence. They also reported high levels of satisfaction and acceptance (Bongarala \& Jayanna, 2019).

In the year 2017-18, the district administration of Mahbubnagar district in the state of Telangana, Southern India, incorporated Brighter Minds program into the existing school curriculum with an aim to enhance cognitive abilities such as attention, observation and memory in the students. The program was rolled out across its twelve residential schools covering 2500 children over a period of one year. These residential schools are run by the government and offer free residential education facilities to the girl students from the rural, poorer and 
disadvantaged communities in the district. A training of trainers (TOT) approach was adopted to scale up the training across all schools. 48 school teachers (4 from each school) were trained in two batches as brighter minds facilitators, and the sessions were integrated into their teaching plans. The district administration was interested in documenting the evidence and hence the Brighter Minds team employed external researchers to study the effects of the program on the students. In this backdrop, the present study was designed to measure the changes in cognition among students that were exposed to the program, with a specific emphasis on attention, memory and observation of students.

\section{Method}

\subsection{Study Design}

The study adopted a mixed methods design having both quantitative and qualitative assessments. Quantitative study captured levels of attention, memory and observation before and after the training was conducted. Qualitative assessments using focus group discussions were carried out after the training to document the observations and experiences of the teachers.

\subsection{Sample Frame}

Ten KGBV (Kasturba Gandhi Balika Vidyalaya) schools and two TSWRS (Telangana Social Welfare Residential Schools) in the district provided sampling frame for the study where program was rolled out during the year 2017-18. These schools offer free residential educational facilities to girl children between $6^{\text {th }}$ and $10^{\text {th }}$ grades. The evaluation was carried out between October 2017 and January 2018. During the time of baseline data collection, 10 children were picked up from each school who were due for the training the following week. The same students were met after the completion of the training for end-line data collect ion. The students were girls of age range seven to 15 years. Only healthy students with normal cognitive functioning have been included in the study.

\subsection{Study Team}

The study was conducted by a team comprising of experts from the background of research and evaluation, psychology, psychiatry, community health and the Brighter Minds intervention team.

\subsection{Tools}

\subsubsection{Quantitative Tools and Outcome Measures}

\subsubsection{Attention Assessments}

Attention was assessed using Make a Trail Test and Stroop Test. The Trail Making test (Partington \& Leiter, 1949) consists of two parts. In the first part (part A) the respondent is asked to connect numbers from 1-25 that are randomly distributed, in a sequence. The second part (part B) of the test requires the respondent to alternate between numbers and alphabets (Llinàs-Reglà, Vilalta-Franch, López-Pousa, Calvó-Perxas, Torrents Rodas, \& Garre-Olmo, 2017). The time taken to complete the exercise reflects the attention (focus) ability of the child.

The Stroop Test (part A) consists of three levels with corresponding charts. In the first level, "Level 1", the participant had to read the words (names of colours), all printed in black font (ex: green, red). In "level 2" of the assessments, the child had to read the words (names of colours) that are now in coloured fonts (colour of font is same as the word). In "level 3", the child has to read the colour of the font, not the word itself. For example, if the word "blue" is written in green coloured font, the participant had to read as "green" instead of "blue." The number of correct responses given in 45 seconds was recorded (Golden, 1978). Level 1 and 2 tests measure attention processing speed and level 3 test measures attention against an interference component. The 3 levels are repeated once again in another format (part B) where the students are assessed for the time they take to read 100 words.

Both the tools i.e. Make a Trail and Stroop tests are widely used to assess attention and are validated for Indian context.

\subsubsection{Observation Assessments}

While standard tools were available to measure attention, the study team had to develop customised tools to measure changes in observation. Since the intervention aimed at improving observation based on visual and non-visual sensory pathways, tools were developed appropriately. The details of the two tools are described below.

\section{Section 1 (Visual sense based observation)}

The tool aimed at capturing the nature of observations made by the child after gazing at a particular object for a certain time period. Initial experience and anecdotal feedback led the intervention teams to hypothesize that the training program enhances the depth of observation and hence the tool was accordingly designed to capture the 
differences in depth of observation before and after the intervention.

The student was given the picture of a child, asked to observe for 45 seconds and write down the observations, either in Telugu (local language) or English. The observations were classified based on the nature of the observation; level 1 for describing physical appearance alone, level 2 for describing emotions and feelings that they felt the child in the picture was experiencing and level 3 for relating the object to the self and describing it as a whole instead of focusing on the object alone.

\section{Section 2 (Non-visual observation and Intuition)}

While section 1 of the tool assessed the ability of the participant to observe and comprehend an object with the support of vision (visual sense), section 2 was designed to capture observations independent of vision. The intervention team had observed that children who completed the training program reported heightened abilities to recognize objects in the surrounding environment without necessarily seeing (blind folded), and often with the support of non - visual based sensory pathways (auditory, tactile, smell, etc.), a phenomena recorded in scientific literature, as Sensory Substitution. This phenomenon was first observed in the blind by a scientist called Paul Bach-y-Rita (Bach-y-Rita \& Kercel, 2003). In recent times, the neurophysiologic mechanisms have been well described with the support of imaging studies (Amedi et al., 2001, 2003; Ptito et al., 2005).

There were also reports by parents and trainers that a number of children can recognize objects without the support of any of the senses, either visual or otherwise, but through the heightened sense of 'feeling' things in the environment. In several contexts, this is referred to as Intuition, a phenomenon where decisions are made without use of rational, analytical thought or inference (Lufityanto, Donkin, \& Pearson, 2016). The brighter minds team believe that the children have naturally ability to use 'feeling' and 'intuition' as yet another instrument of observation, but is suppressed due to lack of adequate use or practice, stress and current day lifestyles that lay emphasis on learning only from outside. The program attempts to restore and develop the intuitive faculty of children as a skill that can complement other instruments of observation and learning. The program hypothesizes that heightened observation including intuition is possible when the children achieve a relaxed and calm state of mind. The program uses its relaxation and music entrainment interventions to achieve the alpha relaxed state of the brain.

The intervention team developed a process for administering blindfolded activity to record these changes. Through a series of experiments and validation checks, the process of administrating the activity, cloth material used for blindfolding the eyes and the test objects were finalized. The tests ranged from identifying an object and its characteristics to reading the text from a book, randomly picked by the assessor. The tool and the process was piloted over 100 children and verified with consistent observations and reports by the parents, trainers and experts, after which the tool and methodology was finalized. The research team used the same tool and process for the study purpose.

During the study, a video demonstrating the steps of the blindfold activity was shown and explained to the students before they were evaluated. The children were blindfolded and coloured objects such as baskets, balls and glasses were given to them one after the other in random manner. They were instructed to report the colour of the object. The trained facilitators made note of the number of correct responses. The entire activity was carried out under the supervision of the lead researcher.

\subsubsection{Memory Assessments}

Memory was assessed using the PGI Memory Scale (PGIMS) which is a standard and reliable measure of memory (Pershad \& Wig, 1994). The scale has been found to be useful especially in academic settings. The scale consists of ten sub-tests- remote memory, recent memory, attention-concentration, delayed recall, immediate recall, verbal retention for similar pairs, and verbal retention for dissimilar pairs, visual retention and recognition.

For the current study, immediate recall, delayed recall, visual retention and visual recognition were used. In the immediate recall subtest, the test-administrator read out few sentences and the participant had to repeat the sentence as precisely as possible. In the delayed recall subtest, the test administrator read names of few objects at the rate of one word per second and asked the participant to repeat it after an interval of one minute. In the visual retention subtest, the participant was shown a card for 15 seconds. After 30 seconds, the participant was required to draw all the things he saw in the card, on the paper. This subtest assesses the individual's ability to retain information which is of visual nature. In the visual recognition test, the participant was shown a card containing pictures of various objects for 30 seconds. After 120 seconds, the test-administrator placed another card in front of the participant. The participant was required to identify and name the objects seen in the previous card. This subtest assesses the individual's ability to recognise events and information that the individual came across. It is 
linked to long-term memory.

\subsubsection{Qualitative Tools and Measures}

Focus group discussions were conducted among teachers to capture their observations and experiences with the cognitive training program. The discussions focused on the changes observed by the teachers in the children, their experience on feasibility and recommendations for scaling this program.

The tools were developed by the team comprising of a psychiatrist, psychologist and the researcher, were pilot tested and validated before using it in the main study.

\subsection{Data Collection and Ethics Approval}

After obtaining permission and approvals from the district administration, the school management and teachers were briefed about the purpose of the study; the students were explained about the process and tools to obtain their consent. Pre- intervention and post-intervention tests were carried out ensuring appropriate auditory and visual privacy in selected places in the schools. The tests were administered directly by the external lead researcher and two other trained research assistants. Pre intervention assessments were carried out in October 2017. The students underwent thirty hours of training for a period of eight weeks during November-December, 2017. Post intervention assessments were carried out with the same students in January 2018. The ethics approval was obtained from the Institutional Ethics Committee of Sri Venkateshwara Hospital, Bangalore.

\subsection{Data Analysis}

Data were analysed using the Statistical Package for Social Science (SPSS) version 16. Only participants who completed both pre-test and post-test assessments were included in the analysis. A paired sample $\mathrm{T}$ test was carried out on pairs of scores for each outcome to determine statistical significance of gains from pre to post-test. The set level of confidence for the acceptance of the study hypothesis was $\alpha=0.05$.

\section{Results}

\subsection{Response Rates and Coverage}

Out of a total of 120 students, 111 (92.5\%) students were available for the post intervention assessments; 9 students missed because they were on leave due to health problems or had moved out to other schools. Finally, data was analysed for 110 students as there were data quality gaps pertaining to one subject. The coverage varied between the tools. Stroop test (Level 1) had lowest response rate $(n=73$ out of $110 ; 66.3 \%)$ and observation tools had the highest $(100 \%)$. Following table presents coverage for each tool

Table 1. Coverage of tools used in the study

\begin{tabular}{llll}
\hline \multirow{2}{*}{ Tool } & & \multicolumn{2}{l}{ Coverage } \\
\cline { 3 - 4 } & & No & $\%$ \\
\hline \multirow{3}{*}{ Attention } & Make a Trail A & 106 & 96.3 \\
& Make a Trail B & 90 & 81.8 \\
& Stroop A: Level 1 & 73 & 66.3 \\
& Stroop A: Level 2 & 107 & 97.2 \\
& Stroop A: Level 3 & 108 & 98.1 \\
& Stroop B: Level 1 & 73 & 66.3 \\
\multirow{2}{*}{ Observation } & Stroop B: Level 2 & 107 & 97.2 \\
& Stroop B: Level 3 & 108 & 98.1 \\
\hline \multirow{3}{*}{ Memory } & Section 1 & 110 & 100 \\
& Section 2 & 110 & 100 \\
\hline & Verbal Immediate & 108 & 98.1 \\
& Verbal Delayed & 108 & 98.1 \\
& Visual Retention & 108 & 98.1 \\
& Visual Recognition & 108 & 98.1 \\
\hline
\end{tabular}


$58 \%$ of the students were in the age group of 10 to 12 years and the remaining (42\%) between 13 and 15 years. The residential schools had only girls. Table 2 represents the frequency and percentage for participant demographics.

Table 2. Age-wise distribution of children

\begin{tabular}{llc}
\hline Demographic Variables & $\mathrm{n}$ & $\%$ \\
\hline Age group $(\mathrm{n}=111)$ & & 57.7 \\
$10-12 \mathrm{y}$ & 64 & 42.3 \\
$13-15 \mathrm{y}$ & 47 & \\
\hline
\end{tabular}

\subsection{Pre and Post Intervention Findings}

\subsubsection{Attention}

The average time taken to complete the Make a Trail test-Part A significantly reduced after the training (59.3 s Vs $47.5 \mathrm{~s}$ ). Time taken to complete part B of the test was significantly lower in the post-intervention group ( $\mathrm{M}=$ $120.4 \mathrm{~s})$ in comparison to the pre-intervention group $(\mathrm{M}=156.6 \mathrm{~s})$. (Table 3a)

Table 3a. Attention scores based on make a Trail Test

\begin{tabular}{|c|c|c|c|c|c|c|c|}
\hline & \multicolumn{2}{|c|}{ Pre-test } & \multicolumn{2}{|c|}{ Post-test } & \multirow{2}{*}{$\mathrm{T}$} & \multirow{2}{*}{ Df } & \multirow{2}{*}{$\mathrm{p}$} \\
\hline & Mean & SD & Mean & SD & & & \\
\hline \multicolumn{8}{|l|}{ (Time taken) } \\
\hline Make a Trail A & 59.3 & 26.6 & 47.5 & 14.0 & 5.1 & 105 & $<0.001$ \\
\hline Make a Trail B & 156.6 & 70.9 & 120.4 & 44.7 & 4.9 & 89 & $<0.001$ \\
\hline
\end{tabular}

The average number of correct items read in 45 seconds in the Stroop test was significantly higher after the training for all three levels. The average time taken to read 100 words was significantly lower for all three charts. (Table $3 \mathrm{~b}$ )

Table 3b. Attention scores based on Stroop test

\begin{tabular}{|c|c|c|c|c|c|c|c|}
\hline & \multicolumn{2}{|c|}{ Pre-test } & \multicolumn{2}{|c|}{ Post-test } & \multirow{2}{*}{$\mathrm{T}$} & \multirow{2}{*}{ Df } & \multirow{2}{*}{$\mathrm{p}$} \\
\hline & Mean & SD & Mean & SD & & & \\
\hline \multicolumn{8}{|c|}{ (No of items read in $45 \mathrm{sec}$ ) } \\
\hline Level 1 & 62.29 & 21.3 & 70.7 & 20.4 & -6.1 & 72 & $<0.001$ \\
\hline Level 2 & 29.3 & 10.8 & 33.3 & 8.4 & -3.4 & 106 & $<0.001$ \\
\hline Level 3 & 49.7 & 26.2 & 57.8 & 23.9 & -4.9 & 107 & $<0.001$ \\
\hline \multicolumn{8}{|c|}{ (Time taken to read 100 words) } \\
\hline Level 1 & 86.4 & 46.7 & 69.4 & 22.7 & 4.5 & 72 & $<0.001$ \\
\hline Level 2 & 179.2 & 46.2 & 148.0 & 34.1 & 8.0 & 106 & $<0.001$ \\
\hline Level 3 & 118.9 & 68.8 & 96.4 & 47.8 & 5.6 & 107 & $<0.001$ \\
\hline
\end{tabular}

\subsubsection{Observation}

More students showed improved depth of observation after the training; 40 students reported level 3 observations as compared to 23 students prior to the program. For blindfolded observation test, mean score of correct responses went up significantly from 6.7 to 9.7 . 
Table 4a. Level of observations before and after intervention

\begin{tabular}{llll}
\hline Level of observation & Pre intervention & Post intervention & Total \\
\hline & 47 & 36 & 41.5 \\
Level 1 (physical appearances) & 41.5 & $(0.73)$ & 83 \\
\hline & $(0.73)$ & 34 & 74 \\
Level 2 (feelings and emotional expressions) & 40 & 37.00 & $(0.24)$ \\
\hline & 37.00 & 40 & 63 \\
Level 3 (relating the object to the personal self) & $(0.24)$ & 31.50 & \\
& 23 & $(2.29)$ & 110 \\
\hline$\chi^{2}=6.532, \mathrm{df}=2, \chi^{2} / \mathrm{df}=3.27, \mathrm{P}\left(\chi^{2}>6.532\right)=0.0382$. & 31.50 & $(2.29)$ &
\end{tabular}

Table 4b. Mean observation scores during the blindfolded tests

\begin{tabular}{|c|c|c|c|c|c|c|c|}
\hline & \multicolumn{2}{|c|}{ Pre-test } & \multicolumn{2}{|c|}{ Post-test } & \multirow{2}{*}{$\mathrm{t}$} & \multirow{2}{*}{ Df } & \multirow{2}{*}{$\mathrm{p}$} \\
\hline & Mean & SD & Mean & SD & & & \\
\hline Observation-Tool 2 & 6.7 & 3.7 & 9.7 & 3.7 & -6.5 & 109 & $<0.001$ \\
\hline
\end{tabular}

\subsubsection{Memory}

Average number of responses for the verbal immediate recall (VIR), verbal delayed recall (VDR) and visual recognition(VC) tests were significantly higher after the training, respectively (VIR $=4.3 \mathrm{Vs} 3.7$; VDR $=3.7 \mathrm{Vs}$ 3.0; $\mathrm{VC}=3.7 \mathrm{Vs} 3.2$ ). However, there were marginal differences for visual retention tests.

Table 5. Memory scores before and after training

\begin{tabular}{|c|c|c|c|c|c|c|c|}
\hline & \multicolumn{2}{|c|}{ Pre-test } & \multicolumn{2}{|c|}{ Post-test } & \multirow{2}{*}{$\mathrm{T}$} & \multirow{2}{*}{$\mathrm{Df}$} & \multirow{2}{*}{$\mathrm{p}$} \\
\hline & Mean & SD & Mean & SD & & & \\
\hline \multicolumn{8}{|l|}{ Verbal } \\
\hline Immediate recall & 3.7 & 1.0 & 4.3 & 0.7 & -4.9 & 107 & $<0.001$ \\
\hline Delayed recall & 3.0 & 1.1 & 3.7 & 0.7 & -6.2 & 107 & $<0.001$ \\
\hline \multicolumn{8}{|l|}{ Visual } \\
\hline Retention & 3.8 & 0.3 & 3.9 & 0.2 & -1.0 & 107 & $=0.277$ \\
\hline Recognition & 3.2 & 0.8 & 3.7 & 0.4 & -5.0 & 107 & $<0.001$ \\
\hline
\end{tabular}

\subsection{Results of the Focus Group Discussions Among Teachers}

In the focus group discussions, the teachers expressed that the students had become calmer and more participatory in the class; they also reported that the students' attention span had increased and were less distracted. One teacher reported that children hesitated to talk to them and even avoided them before the training, but now they expressed their feelings freely, had a more positive attitude towards their friends and teachers. More self-discipline was also reported.

When teachers were asked for their suggestions to improve the program, they expressed that the training program should be conducted regularly and from the beginning of the academic year so the students may experience maximum benefits. 


\section{Discussion}

The present study assessed the impact of a neuro-cognitive cognitive training program on student's attention, observation and memory.

Results indicate that the training program had significant impact on attention that was assessed using the Make a Trail Test and Stroop Test. Such improvements in attention after training are consistent with findings from previous studies (Mozolic, Long, Morgan, Rawley-Payne, \& Laurienti, 2011; Sohlberg \& Mateer, 1987). According to research, students with strong cognitive abilities such as attention shifting, attention control and response inhibition tend to perform well academically in comparison to those students with attention and processing deficits (Biederman et al., 2004). Researchers have made recommendations to rigorously study the impact of the brain trainings on educational outcomes (Rabipour \& Raz, 2012). The quantitative findings from the current study related to cognitive traits correlated with reports of the teachers in the focused group discussions.

Significant improvements in observation abilities were observed in the children after the training. Observation is key to language development, learning various norms and practices and human behaviour. Children everywhere make observations in order to understand and make sense of the world around them (Eberbach \& Crowley, 2009). Children's observational skills are typically thought to be unsystematic, unfocused and unable to make valid inferences. As they mature they tend to notice features, events, people more narrowly and do not automatically notice aggregates and complex, abstract systems. Lehrer and Schauble (2004) showed that fifth graders focused on individual plants instead of focusing on the plant population while tracking plant growth. One possible explanation is that children tend to focus more on the surface features. While there are measurement tools that assess observational ability, tools that measure specifically the degree or depth of observation are lacking and the current study provided opportunities to assess feasibility of such a tool to measure depth of observation and that it is amenable for change with a cognitive training such as Brighter Minds.

Alongside changes in observational abilities, the training led to enhanced intuitive (feeling) capacity in the children. According to Barnard (1938:235) intuition transcends the capacity of merely intellectual methods, and the techniques of discriminating the factors of the situation. Despite the growing amount of acceptance of this idea, little scientific evidence exists that support such phenomena (Lufityanto, Donkin, \& Pearson, 2016). Most intuition studies yield inconsistent results and provide little insight on the mechanism involved. This is because intuition is usually assessed with the help of interviews or survey based techniques (Khatri \& Ng, 2000; Sinclair, Ashkanasy, \& Chattopadhyay, 2010) that focus on the individual's perception (Lufityanto, Donkin, \& Pearson, 2016). Lack of adequately validated tools and process in assessing these phenomena complicates the picture. While there is more that needs to be done in terms of measuring intuition, existing evidence supports that non-conscious emotional information can boost accuracy and confidence while also improving response time (Lufityanto, Donkin, \& Pearson, 2016). The students that participated in the current study did show improved attention, response time and memory that may be linked to non-conscious or intuition processes of the minds.

The brighter minds training achieves the heightened observation including intuition through its music entrainment and relaxation techniques, that helps the children to achieve certain state of relaxation and calm mind. These states as represented by low frequency alpha waves in electro-encephalograph (EEG) studies, have been linked to an increase in working memory representations through the suppression of distracting stimuli present in the environment (Mathewson et al., 2011). Brainwave entrainment consists of applying binaural beats along with stroboscopic light with the help of high-definition audio-video equipment (Cruceanu \& Rotarescu, 2013). In a study by Huang and Charyton (2008) alpha binaural beats were found to lead to an improvement in cognitive abilities. Several studieS have reported that the stable state of mind and raised concentration level as a result of the alpha beats, determines a higher quality in perception (Cruceanu \& Rotarescu, 2013).

With regards to memory tests, the results indicate that immediate recall, delayed recall and visual recognition increased significantly after training. These findings are consistent with previous works that have targeted working memory for training. Klingberg and his team developed a training program to help improve memory in children with ADHD and found marked gains in the students that underwent training (Hill, Serpell, \& Faison, 2015). Melby-Lervag and Hulme (2013) conducted a meta-analytic review of 23 studies that provide evidence for improvements in memory as a result of training (Hill, Serpell, \& Faison, 2015). However, it was found in the current study that there was no significant difference in the average number of responses on the visual retention test This is consistent with previous findings that have shown that long term musical training leads to significant improvements in verbal memory but not of visual memory on account of neuro-plasticity changes in the left temporal lobe (Ho Cheung \& Chan, 2003). Since music is a part of the Brighter Minds Training and the intervention was evaluated over a shorter time frame of 8 weeks, this may be a possible explanation. It may be 
interesting to see if the situation changes over longer periods of training and practice.

The present study shows that students' cognitive capacities can be altered through a neuro-cognitive intervention that was integrated into existing educational curriculum. Several prominent twenty first century scholars advocate that cognitive abilities are modifiable in nature (Feuerstein, Rand, Hoffman, \& Miller, 1980). However, the translation of cognitive gains into long term development of children including academic development has not been adequately studied and needs investigation.

Results of the focus group discussions with teachers who were also the trainers, revealed that the program was not only effective, but also acceptable and feasible in educational settings. According to Bandura (1993) improved application of cognitive abilities in the classroom facilitates better learning experiences, and they not only impact academic performance but also make way for attitudinal change such as increase in self-efficacy, enjoyment and a sense of accomplishment (Hill, Serpell, \& Faison, 2015). In the current study, the school teachers were equipped with skills and training methods that integrated into their existing teaching programs. This differs considerably from other cognitive training programs that are offered as specialized programs which is a limitation to scaling up within existing educational systems and platforms. Particularly, countries like India that is faced with a twin challenge, large scale of the problem coupled with quality gaps, requires trainings and tools that can be integrated seamlessly into existing systems for effective adoption and implementation. This not only achieves scale quickly, but also gains acceptance and ownership of the key stakeholders who have to implement the program as observed in the study.

\section{Limitations and Implications for Future Studies}

One of the Stroop tests (level 1) had poor coverage compared to other tests. The tool requires the subject to read out the word (in English language) as against reading out the colour of the words in the other two stroop tests. While the tools were validated to the local context, they were not translated into local language as all students were exposed to the English language as per the norms. However, few children were not proficient in reading the words in English that may have contributed to the reduced response rate. Another interesting observation is that several students were able to respond to the blind folded activity at the baseline itself. Upon further exploration, it was found out that the subjects in the study while formally had not received the training, they were still exposed to several of the intervention components during practice sessions with other students who had completed the training. Ensuring strict non-contamination in a large scale, residential school setting such as this one was a challenge. However, the additional significant gains in the blind folded assessments among the subjects during the course of formal training, does give insights into the incremental effectiveness of the training. The study examined data collected from children who participated in the training program and does not have an equivalent control group for comparison. An experimental study design with a control arm can provide more robust evidence about effectiveness of the program. The study sheds light on immediate effects of the training on cognitive changes. Furthermore, follow up studies should be carried out to monitor the students' academic, emotional and personality changes in order to get a better understanding of the long term impact of the program on children.

Future studies may also focus on understanding the effects of the training on the neural networks for a biological explanation to the cognitive changes. Additionally, the training can be furthered to the clinical population (especially ADHD and learning disorders) to test its efficiency as a complementary intervention.

\section{Conclusion}

The 'Brighter Minds' training led to significant improvements in several cognitive traits in children, particularly attention, observation and memory which can impact academic performance. This is the first of its kind in India, where a cognitive training program is integrated into existing educational efforts effectively, particularly in a government setting. Policy makers and planners in education sector have invested significant efforts and funds to improve learning outcomes within the school environment. The current study points to a simple, scalable and sustainable intervention that can add value to the existing efforts to achieve educational outcomes related to sustainability development goal (SDG) 4.

\section{Author's Contributions}

SK and KJ conceptualized and designed the study. MB and SK implemented the study on the ground with support from RR and NSN. MB, SK, MR, SB and KJ analysed the data. MB wrote up the first manuscript that was reviewed and finalized by all the co-authors.

\section{Acknowledgements}

The authors acknowledge the support of team members from Mahbubnagar district, support of the teachers and the 
brighter minds facilitators who helped in smooth implementation of the study during the data collection. Dr Smitha M, Assistant Professor in Psychiatry, ESIC Medical College \& Postgraduate Institute of Medical Science and Research, Bangalore, India provided technical input and support in development of the study instruments. Ms Sandhya Basu, PhD student (Psychology) at Birla Institute of Technology and Sciences (BITS), Goa, India provided technical inputs and support in the development of manuscript.

\section{Funding Source and Role of Donor in the Study}

The study was funded by Cognitive Skills Pvt Ltd. The study was designed and implemented by the research team independently.

\section{Conflict of Interests}

Nil.

\section{References}

Amedi, A., Malach, R., Hendler, T., Peled, S., \& Zohary, E. (2001). Visuo-haptic object-related activation in the ventral visual pathway. Nature neuroscience, 4(3), 324. https://doi.org/10.1038/85201

Amedi, A., Raz, N., Pianka, P., Malach, R., \& Zohary, E. (2003). Early 'visual'cortex activation correlates with superior verbal memory performance in the blind. Nature neuroscience, 6(7), 758. https://doi.org/10.1038/nn1072

Bach-y-Rita, P., \& Kercel, S. W. (2003). Sensory substitution and the human-machine interface. Trends in cognitive sciences, 7(12), 541-546. https://doi.org/10.1016/j.tics.2003.10.013

Banerjee, A. V., Cole, S., Duflo, E., \& Linden, L. (2007). Remedying education: Evidence from two randomized experiments in India. The Quarterly Journal of Economics, 122(3), 1235-1264. https://doi.org/10.1162/qjec.122.3.1235

Biederman, J., Monuteaux, M. C., Doyle, A. E., Seidman, L. J., Wilens, T. E., Ferrero, F., ... \& Faraone, S. V. (2004). Impact of executive function deficits and attention-deficit/hyperactivity disorder (ADHD) on academic outcomes in children. Journal of consulting and clinical psychology, 72(5), 757. https://doi.org/10.1037/0022-006X.72.5.757

Bongarala, M., \& Jayanna, K. (2019). Parents' Perspective on Effects and Benefits of "Brighter Minds" Cognitive Training Program: Results from an Online Survey in India. Creative Education, 10, 224-235. https://doi.org/10.4236/ce.2019.101018

Budde, H., Voelcker-Rehage, C., Pietraßyk-Kendziorra, S., Ribeiro, P., \& Tidow, G. (2008). Acute coordinative exercise improves attentional performance in adolescents. Neuroscience letters, 441(2), 219-223. https://doi.org/10.1016/j.neulet.2008.06.024.

Carpenter, D. M., Ledbetter, C., \& Moore, A. L. (2016). LearningRx cognitive training effects in children ages 814: A randomized controlled trial. Applied cognitive psychology, 30(5), 815-826. https://doi.org/10.1002/acp.3257

Chiang, L. C., Ma, W. F., Huang, J. L., Tseng, L. F., \& Hsueh, K. C. (2009). Effect of relaxation-breathing training on anxiety and asthma signs/symptoms of children with moderate-to-severe asthma: a randomized controlled trial. International Journal of Nursing Studies, 46(8), 1061-1070. https://doi.org/10.1016/j.ijnurstu.2009.01.013

Crespo, A., Recuero, M., Galvez, G., \& Begoña, A. (2013). Effect of binaural stimulation on attention and EEG. Archives of Acoustics, 38(4), 517-528. Retrieved from https://www.degruyter.com/downloadpdf/j/aoa.2013.38.issue-4/aoa-2013-0061/aoa-2013-0061.pdf

Cruceanu, V. D., \& Rotarescu, V. S. (2013). Alpha brainwave entrainment as a cognitive performance activator. Cognition, Brain, Behavior, 17(3), 249. Retrieved from https://www.researchgate.net/publication/289030858_Alpha_brainwave_entrainment_as_a_cognitive_perfo rmance_activator

Eberbach, C., \& Crowley, K. (2009). From every day to scientific observation: How children learn to observe the biologist's world. Review of Educational Research, 79, 39-68. https://doi.org/10.3102/0034654308325899

Feuerstein, R., Rand, Y. A., Hoffman, M., Hoffman, M., \& Miller, R. (1979). Cognitive modifiability in retarded adolescents: Effects of instrumental enrichment. American Journal of Mental Deficiency. Retrieved from https://psycnet.apa.org/record/1979-29783-001 
Gao, Z., Podlog, L., \& Huang, C. (2013). Associations among children's situational motivation, physical activity participation, and enjoyment in an active dance video game. Journal of Sport and Health Science, 2(2), 122-128. Retrieved from https://www.sciencedirect.com/science/article/pii/S2095254613000501

Gayatri Mann and Anurag Vaishnav. Committee Report Summary. Draft National Education Policy, 2019. Retrieved from http://www.prsindia.org/sites/default/files/parliament_or_policy_pdfs/Committee\%20 Report\%20Summary\%20-\%20Draft\%20National\%20Education\%20Policy\%20(1).pdf

Golden, C. J., \& Freshwater, S. M. (1978). Stroopcolor and word test.

Gupta, D., \& Gupta, N. (2012). Higher education in India: structure, statistics and challenges. Journal of education and Practice, 3(2). Retrieved from https://s3.amazonaws.com/academia.edu.documents/13141479/11

Hill, O. W., Serpell, Z., \& Faison, M. O. (2016). The efficacy of the LearningRx cognitive training program: modality and transfer effects. The Journal of Experimental Education, 84(3), 600-620. https://doi.org/10.1080/00220973.2015.1065218

Ho, Y. C., Cheung, M. C., \& Chan, A. S. (2003). Music training improves verbal but not visual memory: cross-sectional and longitudinal explorations in children. Neuropsychology, 17(3), 439. https://doi.org/10.1037/0894-4105.17.3.439

Hommel, B., Sellaro, R., Fischer, R., Borg, S., \& Colzato, L. S. (2016). High-frequency binaural beats increase cognitive flexibility: evidence from dual-task crosstalk. Frontiers in psychology, 7, 1287. Retrieved from https://www.frontiersin.org/articles/10.3389/fpsyg.2016.01287/full

Jedlicka, E. J. (2017, November). Learningrx cognitive Training for children and adolescents ages 5-18: effects on academic skills, Behavior, and cognition. In Frontiers in Education (Vol. 2, p. 62). Frontiers. https://doi.org/10.3389/feduc.2017.00062

Khatri, N., \& Ng, H. A. (2000). The role of intuition in strategic decision making. Human Relations, 53(1), 57-86. http://dx.doi.org/10.1177/0018726700531004

Kingdon, G. G. (2007). The progress of school education in India. Oxford Review of Economic Policy, 23(2), 168-195. https://doi.org/10.1093/oxrep/grm015

Kraus, J., \& Porubanova, M. (2017). The Effect of Binaural Beats on Working Memory Capacity. Studia Psychologica, $\quad$ 57(2), 135-145. $\quad$ Retrieved from http://www.studiapsychologica.com/uploads/KRAUS_SP_2_vol.57_2015_pp.135-145.pdf

Lehrer, R., \& Schauble, L. (2004). Modeling natural variation through distribution. American Educational Research Journal, 41(3), 635-679. https://doi.org/10.3102/00028312041003635

Llinàs-Reglà, J., Vilalta-Franch, J., López-Pousa, S., Calvó-Perxas, L., Torrents Rodas, D., \& Garre-Olmo, J. (2017). The Trail Making Test: Association With Other Neuropsychological Measures and Normative Values for Adults Aged 55 Years and Older From a Spanish-Speaking Population-Based Sample. Assessment, 24(2), 183-196. https://doi.org/10.1177/1073191115602552

Lufityanto, G., Donkin, C., \& Pearson, J. (2016). Measuring intuition: nonconscious emotional information boosts decision accuracy and confidence. Psychological science, 27(5), 622-634. https://doi.org/10.1177/0956797616629403

Mathewson, K. E., Lleras, A., Beck, D. M., Fabiani, M., Ro, T., \& Gratton, G. (2011). Pulsed out of awareness: EEG alpha oscillations represent a pulsed-inhibition of ongoing cortical processing. Frontiers in psychology, 2, 99. https://doi.org/10.3389/fpsyg.2011.00099

Mozolic, J. L., Long, A. B., Morgan, A. R., Rawley-Payne, M., \& Laurienti, P. J. (2011). A cognitive training intervention improves modality-specific attention in a randomized controlled trial of healthy older adults. Neurobiology of aging, 32(4), 655-668. https://doi.org/10.1016/j.neurobiolaging.2009.04.013

Padmanabhan, R., Hildreth, A. J., \& Laws, D. (2005). A prospective, randomised, controlled study examining binaural beat audio and pre-operative anxiety in patients undergoing general anaesthesia for day case surgery. $\begin{array}{llll}\text { Anaesthesia, } & 60(9), & \text { 874-877. } & \text { Retrieved }\end{array}$ https://onlinelibrary.wiley.com/doi/full/10.1111/j.1365-2044.2005.04287.x

Padmanabhan, R., Hildreth, A. J., \& Laws, D. (2005). A prospective, randomised, controlled study examining binaural beat audio and pre-operative anxiety in patients undergoing general anaesthesia for day case surgery. Anaesthesia, $60(9)$, 874-877. Retrieved from 
https://onlinelibrary.wiley.com/doi/full/10.1111/j.1365-2044.2005.04287.x

Prakash, V. (2007). Trends in growth and financing of higher education in India. Economic and Political Weekly, 3249-3258.

Retrieved from https://www.jstor.org/stable/pdf/4419875.pdf?refreqid=excelsior\%3Aba02b3686e70286e13f5b23abfc13737

Ptito, M., Moesgaard, S. M., Gjedde, A., \& Kupers, R. (2005). Cross-modal plasticity revealed by electrotactile stimulation of the tongue in the congenitally blind. Brain, 128(3), 606-614. https://doi.org/10.1093/brain/awh380

Rabipour, S., \& Raz, A. (2012). Training the brain: Fact and fad in cognitive and behavioral remediation. Brain and Cognition, 79, 159 179. https://doi.org/10.1016/j.bandc.2012.02.006

Reedijk, S. A., Bolders, A., \& Hommel, B. (2013). The impact of binaural beats on creativity. Frontiers in human neuroscience, $7, \quad 786 . \quad$ Retrieved from https://www.frontiersin.org/articles/10.3389/fnhum.2013.00786/full?utm_source=newsletter\&utm_medium =web\&utm_campaign=Neuroscience-w49-2013

Sinclair, M., Ashkanasy, N. M., \& Chattopadhyay, P. (2010). Affective antecedents of intuitive decision making. Journal of Management \& Organization, 16, 382-398. https://doi.org/10.5172/jmo.16.3.382

Sohlberg, M. M., \& Mateer, C. A. (1987). Effectiveness of an attention-training program. Journal of clinical and experimental neuropsychology, 9(2), 117-130. https://doi.org/10.1080/01688638708405352

\section{Copyrights}

Copyright for this article is retained by the author(s), with first publication rights granted to the journal.

This is an open-access article distributed under the terms and conditions of the Creative Commons Attribution license (http://creativecommons.org/licenses/by/4.0/). 